\title{
The emergence of stable isotopes in environmental and forensic geochemistry studies: a review
}

\author{
R. Paul Philp
}

Received: 28 April 2006 / Accepted: 28 July 2006 / Published online: 16 August 2006

(C) Springer-Verlag 2006

\begin{abstract}
In the past decade, environmental forensics has emerged as a discipline directed toward determining parties liable for causing spills of contaminants into the environment. Such investigations, while geared toward determining the guilty parties in order to recover costs of the cleanup and remediation, require various questions to be addressed. These include determination of the nature of the product; Where did it come from?; Extent of weathering, if any; How long has it been there?; and Is it degrading naturally? Traditionally, these studies have been addressed through utilization of techniques such as gas chromatography (GC) and gas chromatography-mass spectrometry (GCMS). However, in recent years, stable isotopes, primarily determined through the use of combined gas chromatography-isotope ratio mass spectrometry (GCIRMS), have emerged as an equally important tool in environmental forensics. For relatively low molecular, volatile compounds such as MTBE, BTEX, or chlorinated solvents, the isotopes, primarily carbon and hydrogen, have been used extensively for evaluating the onset of natural attenuation. For larger molecules such as PCBs or PAHs, in which the effects of biodegradation on the isotope composition of these molecules is minimal, the isotopic fingerprints of the individual compounds can be used for correlation purposes. In this paper, a brief introduction to isotope geochemistry will be given, followed by a review of applications of stable isotopes to a variety of environmental problems. While the review may not necessarily be exhaustive, it will provide a comprehensive overview of areas where isotopes have been used and potential applications for the future. Most of the review is concerned with carbon and hy-
\end{abstract}

R. P. Philp $(\bowtie)$

School of Geology and Geophysics, University of Oklahoma,

Norman, OK 73019, USA

e-mail:pphilp@ou.edu drogen isotopes, although a brief overview of the emerging area of chlorine isotopes will also be discussed.

Keywords Stable isotopes - Environmental - Forensic · GCIRMS · Carbon · Chlorine · MTBE · PCE · PCBs · PAHs

\section{Introduction}

The past decade has seen an exponential increase in the number of forensic geochemical applications in the literature and utilized in litigation. The reasons for this are numerous, but two, in particular, should be noted. First, many of the techniques developed for correlation of crude oils and suspected source rocks, or other oils, based on the biomarker concept are used routinely in forensic applications for correlation of spilled products, both crude oils and refined products. Second, the past decade has seen a tremendous increase in the number of isotope applications to forensic problems. Determination of stable isotopes is not new, having been around for over 50 years. The ability to determine the isotopic composition of individual compounds in complex mixtures is relatively new and came about with the development and commercial availability of combined gas chromatograph-isotope ratio mass spectrometers (GCIRMS) in the late 1980s and early 1990s. Initially, only carbon isotopes could be determined with this approach, but now it is possible to determine hydrogen and nitrogen isotopes in the same manner.

The developments in isotope geochemistry have lead to significant advances in the ability to undertake source determinations at contaminated sites; unravel commingled plumes of contaminants; and monitor natural attenuation at contaminated sites. Any forensic geochemistry study is basically directed toward answering three or four major questions:

1. What is the product(s)? 
2. Where did it come from?

3. How long has it been there?

4. Is it going away or degrading naturally?

These four questions, to some degree or other, are geared to answering the ultimate question: Who is going to pay for the cleanup?

This paper will address how the use of stable isotopes has evolved as a tool that can assist in addressing the first four questions. It is important to emphasize that wherever possible, the isotopic data must be combined with complimentary fingerprint data available from techniques such as gas chromatography-isotope ratio mass spectrometry (GCMS).

Sources and types of contaminants in the environment and resulting problems are many and varied and include natural seepage of crude oils, ship traffic, supertankers spilling crude oils, leaking storage tanks, pipelines, hydrocarbons, polychlorinated biphenyls (PCBs), pesticides, dioxins, and many other types of chemical spills from a wide variety of sources (Aislabie et al. 2004; Alzaga et al. 2004; Ohe et al. 2004; Chapman and Riddle 2005; Franco et al. 2006; Hong et al. 2005; Lee et al. 2005; Chen et al. 2006; Samara et al. 2006). In certain cases, characterization of these spills by GC and GCMS data may be ambiguous, and inconclusive, as result of weathering processes such as evaporation, photooxidation, water-washing, and biodegradation changing the distribution of components in the spilled material versus the original sample (Milner et al. 1977; Lafargue and Barker 1988; Palmer 1993). Depending on the nature of the compounds involved and environmental conditions, evaporation may occur in the first few hours after a spill and remove the more volatile components. If the incident occurs in an aquatic environment, water-washing will remove the more water-soluble components from crude oils or refined products, such as hydrocarbons below $\mathrm{C}_{15}$, and some of the $\mathrm{C}_{15+}$ aromatic compounds, which are more water-soluble than paraffins (Lafargue and Barker 1988; Palmer 1993; Fuentes et al. 1996). At the same time, biodegradation may start to affect the distribution of individual compounds, although the rate will depend on the nature of the spill and environment into which it spilled (Thornton et al. 2001; Brenner et al. 2002; Gray et al. 2002; Mancini et al. 2002; Meckenstock et al. 2002; Schüth et al. 2003; Griebler et al. 2004; Schirmer and Butler 2004; Kuder et al. 2005; Haws et al. 2006).

Correlation of spilled material with suspected sources, whether hydrocarbon-based, or of some other chemical origin, requires discriminative parameters that are relatively insensitive to weathering processes. In recent years, stable isotope compositions, typically carbon or hydrogen isotopic values, have been used to provide an additional and complimentary tool for correlation purposes (Hartman and Hammond 1981; Macko et al. 1981; Macko and Parker 1983; Farran et al. 1987; Wassenaar and Hobson 2000; Pond et al.
2002; Fang et al. 2002; Wang et al. 2004; Glaser et al. 2005; Gürgey et al. 2005; Horii et al. 2005; Wen et al. 2005). In selected cases, chlorine, nitrogen, oxygen, or sulfur isotope compositions have also been used (Warmerdarm et al. 1995; Sturchio et al. 1998; Beneteau et al. 1999; Reddy et al. 2000; Coffin et al. 2001; Jendrzejewski et al. 2001; Drenzek et al. 2002; Numata et al. 2002; Shouakar-Stash et al. 2003, 2005; Philp et al. 2002; Pond et al. 2002; Griebler et al. 2004; Kuder et al. 2005; Zwank et al. 2005). Potential areas of environmental chemistry that may also benefit from incorporation of stable isotopes as an additional analytical tool can be found in a recent monograph (Lichtfouse et al. 2005). It should also be noted that utilization of isotopes is not restricted to environmental problems and applications to other areas were summarized in a review article by Lichtfouse (2000).

\section{Isotope geochemistry}

\section{Principles}

For a comprehensive overview of stable isotope chemistry, the reader is advised to consult some of the excellent textbooks recently published in this field (Melander and Saunders 1980; Galimov 1985; Hoeffs 2004; Faure and Mensing 2005). The elements that comprise molecules of common organic contaminants (such as $\mathrm{C}, \mathrm{H}, \mathrm{O}, \mathrm{N}, \mathrm{S}$, and $\mathrm{Cl}$ ) each have at least two stable isotope species. In the recent decades, isotope data published in earth and environmental sciences are reported relative to the same international standard using the delta notation. Delta units are referred to as $\%$, or permil, and represent deviation of the measured ratio versus the international standard. In case of carbon, the ratio of ${ }^{13} \mathrm{C}$ to ${ }^{12} \mathrm{C}$ is represented in the delta notation as follows:

$\delta^{13} \mathrm{C}=\left(\frac{R_{\text {sample }}}{R_{\text {standard }}-1}\right) \times 1000$

where $R$ is ${ }^{13} \mathrm{C} /{ }^{12} \mathrm{C}$, and the standard is VPDB, or Vienna Pee Dee Belemnite.

For bulk isotope values, the sample to be characterized is placed in a sealed glass tube with a small amount of $\mathrm{CuO}$. The tube is evacuated, sealed, and combusted at $600^{\circ} \mathrm{C}$ for several hours to ensure complete combustion of all the organic material in the sample. The tube is attached to the vacuum line and opened under vacuum, water is removed, and $\mathrm{CO}_{2}$ is pulsed into the isotope ratio mass spectrometer along with the standard gas and the relative proportions of the ${ }^{12} \mathrm{CO}_{2}$ and ${ }^{13} \mathrm{CO}_{2}$ measured and ultimately converted into a $\delta^{13} \mathrm{C}$ value using the previous equation.

Isotope values of organic compounds will vary for a variety of reasons. Carbon exists as a mixture of two stable isotopes, ${ }^{12} \mathrm{C}$ and ${ }^{13} \mathrm{C}$, with the approximate natural abundance of ${ }^{12} \mathrm{C} /{ }^{13} \mathrm{C}$ ratio being 99:1. The carbon isotopic composi- 
tion of living organic matter, in part, not only depends on the species but is also determined by a number of environmental properties. Atmospheric carbon dioxide is assimilated by living plants during photosynthesis. The nature of the plants and whether they assimilate $\mathrm{CO}_{2}$ via a $\mathrm{C}_{3}$ or $\mathrm{C}_{4}$ photosynthetic cycle determines the extent of preferential assimilation of the lighter ${ }^{12} \mathrm{C}$ isotope, resulting in a 5-25\%o depletion in ${ }^{13} \mathrm{C}$. The $\mathrm{C}_{4}$ plants are typically associated with warmer and more arid climates and, in general, have isotopic values in the -10 to $-18 \%$ range. The $\mathrm{C}_{3}$ plants, representing $85 \%$ of plant species and dominating most terrestrial ecosystems, are generally associated with cooler and wetter climates and have lighter isotopic values in the -22 to $-30 \%$ range. The natural vegetation in temperate and high-latitude regions, as well as tropical forests, is almost exclusively $\mathrm{C}_{3}$ along with major crops such as wheat, rye, barley, legumes, cotton, tobacco, tubers (including sugar beets), and fallow grasses. The $\mathrm{C}_{4}$ plants represent less than $5 \%$ of floral species but dominate in hot open ecosystems such as tropical and temperate grasslands and include common crops such as sugar cane, corn, and sorghum. Desert plants such as cacti operate under yet another mechanism of photosynthesis referred to as the CAM photosynthesis cycle and can operate under both the $\mathrm{C}_{3}$ and $\mathrm{C}_{4}$ cycles.

In summary, the stable isotopic composition of any compound or material reflects of the relative proportions of the two stable isotopes and a measure of how depleted the compound or material is in the heavier isotope relative to a standard. These isotopic source differences are ultimately responsible for the isotopic differences in organic contaminants, most of which are derived from crude oils. The crude oils, in turn, have different isotope signatures as a result of the varying source inputs.

\section{Isotope fractionation}

Changes of isotope ratios caused by various chemical or physical processes are referred to as isotope fractionation or isotope effects. Kinetic isotope effects from degradation result from the different reaction rates for ${ }^{13} \mathrm{C}$ and ${ }^{12} \mathrm{C}$ isotopes. The presence of the heavier isotope in the bond targeted by the degradation increases the bond cleavage activation energy and, as a consequence, reduces the rate of degradation. During the progress of degradation, the residual substrate becomes progressively enriched in the "heavier" isotope species (i.e., ${ }^{13} \mathrm{C} /{ }^{12} \mathrm{C}$ increases). Degradationrelated isotope effects are strong for the atoms included in the chemical bond being broken (primary isotope effects), while the remaining atoms experience weak secondary isotope effects. Isotope effects resulting from biodegradation reflect the first rate-limiting step of the reaction sequence. Biodegradation isotope effects typically are limited to small molecules, readily permeating cell membranes of degrad- ing organisms. Biodegradation of chlorinated ethanes and ethanes, methyl tert-butyl ether (MTBE), and monoaromatic compounds have been most widely studied, and isotope fractionation has been observed. Typically, biodegradation of semivolatiles such as long chain $n$-alkanes, multi-ring PAHs (polyaromatic hydrocarbons), and PCBs does not result in measurable isotope fractionation. This, in turn, has advantages, since with the larger molecules, this means that the isotope fingerprints from those compounds can be used for correlation purposes.

\section{Bulk isotope values}

The bulk isotopic composition of a contaminant, such as a crude oil, represents a weighted average of the isotopic composition of all components in a mixture. For crude oils, correlations can be made using the bulk isotopic compositions of the saturate and aromatic fractions rather than the whole oil itself. A cross plot of the isotopic values for the saturate and aromatic fractions will show that samples related to each other will plot very close to each other, while those that are not related will plot in totally different areas. The use of bulk isotopes in this manner is a preliminary screening tool and simply because two samples plot close to each other does not necessarily mean that they are unequivocally related to each other. Once a preliminary relationship between samples has been established, more definitive correlations should be undertaken using techniques such as GC and GCMS.

A classic example of the use of bulk carbon isotopes in a forensic type study would be from the work of Kvenvolden et al. (1995). Tar ball residues from the beaches of Prince William Sound were collected several years after the Exxon Valdez accident and characterized on the basis of their bulk carbon isotope ratios. Based on the bulk isotope values for several residues, two distinct families of tar ball residues could be identified. One family corresponded closely to the Exxon Valdez oil with carbon isotope values around $-29 \%$. The second group was isotopically heavier with values around $-24 \%$, and based on these values plus the biomarker data, it was concluded that this group was derived from Californian crude oils derived from the Monterey Formation. The California crude was imported into Alaska prior to 1964 when a massive earthquake struck the region of Valdez, the tanks ruptured, and the oil spilled into the Sound, where it was left to degrade naturally. Bulk isotope values have been used in many other areas of forensic investigations including determination of the geographic origin of illicit drugs, adulterated foodstuffs, diluted liquor, synthetic drugs, and many others (Hillaire-Marcel 1986).

However, bulk isotope values have limited application, since they reflect a weighted average of the isotopic compositions of all the compounds in a sample. Furthermore, with 
volatile spills, there is the possibility that evaporation will alter the spilled mixture to such a degree that it will no longer be possible to make correlations based on the bulk isotope values.

Several years ago, the combination of the gas chromatograph and isotope ratio mass spectrometer was finally achieved, and from that point on, it was possible to obtain the isotopic compositions of individual compounds in complex mixtures (Hayes et al. 1990). This provided the opportunity to obtain an isotopic fingerprint which, in the case of complex mixtures, could be used as an additional correlation tool. In the case of single components, it might be the only correlation tool available. The following sections will provide some examples of where this approach has been used in an ever expanding number of applications.

\section{Isotopic compositions of individual compounds determined by GCIRMS}

Solvent extractable fractions and free products

In a typical GCIRMS analysis to determine carbon isotope compositions, chromatographic separation is followed by online high-temperature conversion of individual compounds to $\mathrm{CO}_{2}$ which passes into a continuous-flow IRMS for isotope ratio determination (Merritt et al. 1995). Similar methods are followed for hydrogen (Burgoyne and Hayes 1998). Determination and utilization of chlorine isotopes have been reviewed and discussed by Slater (2003), Schmidt et al. (2004), Meckenstock et al. (2004a,b), and Scow and Hicks (2005). Compound-specific analysis of $\mathrm{Cl}$ (Holt et al. 1997) and $\mathrm{Br}$ (Shoukar-Stash et al. 2005) is only possible after offline chromatographic separation of the target analytes and offline chemical processing to IRMS-amenable gaseous products $\left(\mathrm{CH}_{3} \mathrm{Cl}\right.$ and $\mathrm{CH}_{3} \mathrm{Br}$, respectively). Two different concepts of interfacing LC (liquid chromatography) and IRMS have been proposed (Caimi and Brenna 1993; Krummen et al. 2004) but no applications of LC-IRMS to contaminant studies are available at present.

For aqueous, volatile range organic contaminants, optimal results are obtained with a purge-and-trap interfaced to the GCIRMS instrument (Zwank et al. 2003; Kuder et al. 2005). Excellent quantitation limits, in low microgram per liter range or even nanogram per liter for certain species, are possible with this approach. $\delta^{13} \mathrm{C}$ values for benzene, toluene, etc. have been determined at concentrations of approximately $700 \mathrm{ng} / \mathrm{l}$ and MTBE at $1.5 \mu \mathrm{g} / \mathrm{l}$ using purgeand-trap. Limits of detection are slightly higher for polar contaminants-e.g., $200 \mu \mathrm{g} / \mathrm{l}$ for ethanol and $20 \mu \mathrm{g} / \mathrm{l}$ for tertbutyl alcohol (TBA). Hydrogen isotope ratios can also be determined by purge-and-trap but concentrations need to be approximately 10 times higher than for carbon determi- nation. By comparison, carbon isotope analysis of volatile species via headspace analyses requires concentrations in the range of $500 \mu \mathrm{g} / \mathrm{l}$ or more (detection limits from Hunkeler and Aravena 2000). Solid-phase microextraction (SPME) is an improvement over headspace analysis and permits better detection limits but is still not a reproducible as purge-andtrap (e.g., Hunkeler and Aravena 2000).

Chemical fingerprinting of the $n$-alkane fraction in crude oils and refined products in combination with isotopic characterization of carbon in the individual homologues has been used successfully to allocate sources of sediment contamination (Mansuy et al. 1997; Rogers et al. 1999; Abrajano and Sherwood Lollar, 1999; Smallwood et al. 2002) and oiling of bird feathers (Mansuy et al. 1997; Mazeas and Budzinski 2002). Hough et al. (2006) used the $\delta^{13} \mathrm{C}$ values of individual $n$-alkanes to identify the source of hydrocarbons in soils contaminated with heavily weathered petroleum wastes.

Pond et al. (2002) proposed the use of hydrogen isotopic composition of longer chain $n$-alkanes $\left(n-\mathrm{C}_{19}\right.$ to $\left.n-\mathrm{C}_{27}\right)$ for source discrimination, since the hydrogen isotopic signature of crude oil components vary more significantly than the carbon values and do not show discernable changes during weathering or degradation of crude oils. There have been a number of applications in the petroleum geochemistry literature describing the use of both the $\mathrm{C}$ and $\mathrm{H}$ isotope values of crude oils and saturate hydrocarbon fractions for undertaking oil/oil and oil/source rock correlation studies (Peters and Fowler 2002; Philp et al. 2002; Milkov 2005). However, the number of applications of H/D determinations in the environmental field has been fairly limited and most of them have been simply designed to show applicability of the technique (Hilkert et al. 1999; Sessions et al. 1999; Wiesenberg et al. 2004).

GCIRMS is particularly important in the case of refined products such as gasolines, which may be derived from different feedstocks but may be very similar chromatographically and difficult to discriminate using conventional techniques such as GC and GCMS. In early environmental applications of GCIRMS, Kelley et al. (1995, 1997) measured the concentrations and isotopic compositions of BTEX (benzene, toluene, ethylbenzene, and xylene) compounds collected from a gasoline contaminated site in Southern California. From the results, it was evident that there were two isotopically distinct families of BTEX compounds, permitting one to draw the conclusion that the leaded and unleaded gasoline at this site were derived from different sources. Since that initial report, Smallwood et al. (2002) published a study demonstrating that for gasolines derived from different crude oil feedstocks, an isotopic fingerprint of individual compounds in the gasolines could be used to discriminate the gasolines. It is important to emphasize that this approach is not necessarily going to work every time but, at 
the same time, the more conventional GC and GCMS will probably not discriminate the samples either if GCIRMS is unsuccessful.

Polycyclic aromatic hydrocarbons in the environment may be derived from sources such as coal tar, crude oils, or creosotes for example. In many cases, the chromatographic distributions of these compounds from different sources may be very similar and of little use in terms of distinguishing one source from another. In addition, weathering can often result in additional ambiguities. However, with the development of GCIRMS, the possibility of determining the isotopic composition of the individual components provides a potential method for differentiating these sources of the PAHs. On a regional scale, source apportionment of PAHs both in the atmosphere and in sediment records has been studied intensely using $\delta^{13} \mathrm{C}$ analysis. A combination of concentration measurements and $\delta^{13} \mathrm{C}$ isotopic analysis of individual PAHs in sediments from Lake Erie permitted three areas with different contamination histories to be distinguished with the main emission pathway for PAHs being fluvial input (Smirnov et al. 1998). A comprehensive study to evaluate the use of stable isotopes to differentiate PAHs derived from urban backgrounds versus those derived from coal gasification plants has been recently completed (Saber et al. 2003, 2005; Craig et al. 2005; Mauro et al. 2005). PAH samples that appear similar chromatographically may be differentiated on the basis of their isotopic signatures, and similarly those that are isotopically different may be chromatographically similar. Furthermore, the isotopic signatures of samples derived from the manufactured gas plants are distinct from those typically derived from PAHs from the urban background signature (Figure 4.13). Hammer et al. (1998) studied the PAHs from two creosote-contaminated sites and showed that at those sites, there was a suite of compounds that had isotopic values within $1 \%$ of each other and could be useful in the identification of PAHs of creosote origin. Various sources of PAHs were distinguished in sediments along the St. Lawrence River with relatively heavy $\delta^{13} \mathrm{C}$ values found for the three-ring PAHs originating from an aluminum smelter in one area (Stark et al. 2003). McRae et al. (1999, 2000) showed it was possible to relate coal-derived PAHs released during different thermal conversion processes (combustion, pyrolysis, and gasification) with their isotopic compositions conserved in soil PAHs. Extremely isotopically light PAHs ( $\delta^{13} \mathrm{C}$ from -31 to $-62 \%$ ) in lagoon sediments near Ravenna (Italy) led to the conclusion that emissions were dominated by a former plant that used biogenic methane $\left(\delta^{13} \mathrm{C}\right.$ from -69 to $-73 \%$ ) as feedstock rather than by operating plants using petrogenic feedstocks that typically are isotopically heavier (McRae et al. 2000). Wilcke et al. (2002) used $\delta^{13} \mathrm{C}$ analysis of perylene to substantiate their earlier hypothesis that recent biological sources of PAHs related to termites are important in tropical environments, whereas py- rolytic sources dominate in temperate climates. PAHs in atmospheric particles resulting from natural burning processes could be distinguished from those stemming from various anthropogenic combustion processes by using fingerprinting and $\delta^{13} \mathrm{C}$ analysis of individual compounds (Norman et al. 1999; Okuda et al. 2002a). In Chinese urban areas, $\mathrm{PAH} \delta^{13} \mathrm{C}$ analysis was successfully used to identify either vehicle exhaust or coal combustion as major PAH source (Okuda et al. 2002b). In contrast, PAH fingerprinting by GC did not yield equivalent information. Many of these studies show the necessity to combine chemical fingerprinting techniques and compound-specific isotope analysis.

\section{Characterization of chlorinated compounds}

The widespread occurrence and stability of chlorinated contaminants in the environment, PCBs, dioxins, dichlorodiphenyl-trichloroethane (DDT), and a wide variety of other compounds has lead to an increased interest in the possible use of the chlorine isotope ratios as a means of studying the origin, transport, and fate of these compounds in the environment. The topic of chlorinated solvents can be divided into two areas-nonvolatiles such as PCBs, etc. and volatiles such as perchloroethylene (PCE) and trichloroethylene (TCE), which are common groundwater contaminants. Reddy et al. (2000) studied a number of PCBs from a variety of sources and noted that the $\delta^{37} \mathrm{Cl}$ values fell within a narrow range from -3.4 to $2.1 \%$ but found no correlation between the mass percent of chlorine and $\delta^{37} \mathrm{Cl}$ values. It should be noted that the samples used in this particular study were obtained from environmental standard suppliers who, in turn, had obtained the materials from Bayer (Germany) and Caffaro (Italy). The variability observed in the standards was suggested to arise from differences in the starting materials, synthetic methods, purification, or postproduction storage and handling of these products or some combination of these factors. PCBs extracted from sediments ranged from -4.54 to $-2.25 \%$. These isotopic variations suggest that $\delta^{37} \mathrm{Cl}$ could be a useful tool for tracing the sources and fate of PCBs. In a laboratory study that monitored the aerobic degradation of dichloromethane (DCM), Heraty et al. (1999) noted that the $\delta^{37} \mathrm{Cl}$ values of the residual DCM increased as a function of biodegradation.

In another slightly different approach with PCBs, Jarman et al. (1998) examined the carbon isotope variations for individual congeners in a variety of commercial PCBs. The bulk carbon isotope values for individual PCBs varied from -22.34 to $-26.95 \%$, whereas individual congeners showed values ranging from -18.65 to $-27.98 \%$. Large differences were observed for individual congeners between mixtures. Individual congeners showed a depletion of ${ }^{13} \mathrm{C}$ with increasing chlorine content, probably as result of a kinetic isotope effect caused by the position of the chlorine 
atom on the biphenyl molecule. Such a wide diversity of carbon isotope values could prove to be very powerful in determining the source for PCBs in the environment.

In the past few years, attention has turned to the more volatile chlorinated compounds such as PCE, TCE, and related degradation products. Since the 1940s, these chlorinated hydrocarbons have been used in a variety of industries such as electronic, instruments manufacturing, aerospace, machinery, printing, and dry cleaning (Beneteau et al. 1999; Hunkeler et al. 1999; Jendrzejewski et al. 2001).

Hunkeler et al. (1999) presented $\delta^{13} \mathrm{C}$ values of PCE and its dechlorination products from microcosms and field samples. The pattern of isotope fractionation matched complete dechlorination of PCE in the microcosm and a similar pattern was observed in the field data set. Sherwood Lollar et al. (2001) studied stable carbon isotope fractionation of TCE and PCE at Dover AFB (USA). Isotope fractionation of TCE, in particular, was indicative of extensive dechlorination. Song et al. (2002) used Compound-specific isotope analyses (CSIA) to monitor TCE dechlorination in a pilot study of in-situ lactate amendment (at a test site of Idaho National Engineering and Environmental Laboratory, USA). CSIA results confirmed quantitative conversion of TCE to ethene. Hunkeler et al. (2005) presented data on a chlorinated hydrocarbon plume study (at an undisclosed former solvent disposal site). The typical reductive dechlorination of chlorinated ethenes was found to be of minor importance, and the predominant reaction pathways were dehydrochlorination of 1,1,2,2-PCE to TCE, reductive dechlorination of chloroform to dichloromethane, dichloroelimination of 1,1,2-TCA (trichloroethane) to vinyl chloride (VC), and dichloroelimination of 1,2-DCA (dichloroethane) to ethene. Morrill et al. (2005) showed that enrichment of ${ }^{13} \mathrm{C}$ in cis-DCE validated in-situ dechlorination of the compound in a bioaugmentation project (Kelly AFB, USA). Recently, Chartrand et al. (2005) used CSIA to monitor reductive dechlorination process in a fractured bedrock plume during a pilot-scale bioaugmentation project. Chlorinated ethene concentration profiles were not convincing evidence for the progress of dechlorination due to variable hydraulic gradients in the fractured bedrock and ongoing flux of contaminants from the NAPL source. However, enrichments of ${ }^{13} \mathrm{C}$ in cis-DCE and VC were indicative of dechlorination, and a quantitative estimate of the CSIA data permitted to evaluate the efficiency of bioaugmentation treatment.

\section{MTBE}

Gasoline oxygenates, particularly MTBE, represent a significant groundwater contamination problem but one well suited for isotope studies. A number of studies have shown MTBE degradation in anaerobic microcosms and in the field, under a range of electron acceptor conditions (Bradley et al. 1999;
Finneran et al. 2001). Degradation under anaerobic conditions (Somsamak et al. 2001) is slower and, in most cases, may be restricted to biotransformation of MTBE to TBA. As a consequence, natural attenuation of anaerobic plumes tends to be relatively slow, resulting in the accumulation of TBA as MTBE disappears.

Kolhatkar et al. (2002) showed enrichment of ${ }^{13} \mathrm{C}$ in an anaerobic MTBE plume at a retail gasoline station in New Jersey, USA. Kuder et al. (2005) presented combined carbon and hydrogen CSIA data for nine MTBE sites (gasoline retail stations in California and New Jersey, USA) and from attendant microcosm experiments. The isotopic enrichments were indicative of biodegradation, and the two-dimensional isotope fractionation pattern was indicative of anaerobic biodegradation pathway for all of the sites studied. The pattern of isotope fractionation was indicative of demethylation for MTBE to TBA. Assessment of the progress of in-situ degradation based on the Rayleigh model demonstrated significant removal of MTBE, exceeded $90 \%$ for some of the samples. Zwank et al. (2005) presented carbon and hydrogen data set from a chemical waste storage site in Brasilia and reached similar conclusions on the MTBE degradation pathway. Day et al. (2002) showed an increase in the $\delta^{13} \mathrm{C}$ values for TBA corresponding to plume downgradient concentration reduction at an undisclosed chemical plant in the United States. This appears to be the only available example of CSIA confirmation of in-situ TBA degradation that has been published to date.

The most important application for the isotope values, in addition to source evaluation or correlation, would be monitoring the rate and/or extent of biodegradation of individual compounds in the environment. The potential of this approach is enormous, particularly in the case of groundwater samples and specifically for compounds that are very soluble in water such as MTBE (Gray et al. 2002). One of the problems with compounds such as MTBE is that they are mobile and concentration changes at the monitoring wells do not necessary reflect changes in concentrations resulting from biodegradation. The changes in concentration at a specific water well may simply reflect movement of the compounds of interest within the plume. However, the potential of this approach has been demonstrated in a number of field and laboratory studies, both published and unpublished. For example, in a number of studies from our laboratory, and others, it has been shown that MTBE becomes progressively heavier isotopically with increasing biodegradation (Gray et al. 2002; Mancini et al. 2003; Chartrand et al. 2005; Kuder et al. 2005). This effect has now been observed at many sites and appears to be reproducible. In their papers, Meckenstock et al. $(1999,2002)$ used toluene as a substrate to demonstrate that isotopic enrichments of up to $10 \%$ could be observed, depending on the particular strain of bacterium being utilized. 


\section{Summary}

For many years, it was only possible to determine the bulk isotopic composition of a mixture of compounds. Bulk isotope values were used extensively in the petroleum industry and for a variety of other applications. However, for complex mixtures, bulk isotope values have been of limited use, since they represent weighted averages of all the compounds in the mixture. Hence, it was fortuitous for environmental geochemistry, and other areas, when the combination of the gas chromatograph-isotope ratio mass spectrometer was developed. Now it is possible to determine isotopic composition of individual compounds in complex mixtures at relatively low concentrations. These values can be used for correlation purposes of monitoring natural attenuation in groundwater studies. This paper has attempted to summarize many of the important papers that have appeared as a result of these developments. There are many others but, in general, it is felt the information here will provide a good overview of the developments and applications that have taken place in the past few years.

In environmental forensic studies, stable isotopes are being used to determine sources or monitor natural attenutation. One has to determine whether or not any degradation has occurred prior to using the isotope fingerprints for correlation purposes, since the only significant process to alter the isotope ratio of the contaminant is degradationbiodegradation or abiotic chemical degradation. If no degradation is occurring, isotope fingerprinting can be considered as a reliable source-tracking tool. Qualitative verification of in-situ biodegradation only requires that isotope fractionation is confirmed relative to the initial source isotope ratio (enrichment of the heavier isotope, e.g., increase of $\delta^{13} \mathrm{C}$ value).

In brief, the exponential increase in applications and utilization of stable isotopes in environmental studies bodes well for the future of this technique. With time, procedures for determination of other isotopes will become routine. Carbon and hydrogen are already routine and before long it can be assumed that a method will also be developed for online determination of chlorine. It is not proposed that the isotope data should be used on its own but rather as a complimentary tool for use in conjunction with the established techniques of GC and GCMS.

\section{References}

Abrajano J, Sherwood Lollar B (1999) Compound-specific isotope analysis: tracing organic contaminant sources and processes in geochemical systems. Org Geochem 30(8B):v-vii

Aislabie JM, Balks MR, Foght JM, Waterhouse EJ (2004) Hydrocarbon spills on Antarctic soils: effects and management. Environ Sci Technol 38(5):1265-1274
Alzaga R, Montuori P, Ortiz L, Bayona JM, Albaigés J (2004) Fast solidphase extraction-gas chromatography-mass spectrometry procedure for oil fingerprinting: application to the Prestige oil spill. J Chromatogr A 1025(1):133-138

Beneteau KM, Aravena R, Frape SK (1999) Isotopic characterization of chlorinated solvents-laboratory and field results. Org Geochem 30(8):739-753

Bradley PM, Landmeyer JE, Chapelle FH (1999) Aerobic mineralization of MTBE and tert-butyl alcohol by stream-bed sediment micro-organisms. Environ Sci Technol 33(11):1877-1879

Brenner RC, Magar VS, Ickes JA, Abbott JE, Stout SA, Crecelius EA, Bingler LS (2002) Characterization and fate of PAH-contaminated sediments at the Wyckoff/Eagle Harbor superfund site. Environ Sci Technol 36(12):2605-2613

Burgoyne TW, Hayes JM (1998) Quantitative production of $\mathrm{H}_{2}$ by pyrolysis of gas chromatographic effluents. Anal Chem 70:51365141

Caimi RJ, Brenna JT (1993) High-precision liquid chromatographycombustion isotope ratio mass spectrometry. Anal Chem 65:3497500

Chapman PM, Riddle MJ (2005) Toxic effects of contaminants in polar marine environments. Environ Sci Technol 39(9):200A206A

Chartrand MMG, Morrill PL, Lacrampe-Couloume G, Sherwood Lollar B (2005) Stable isotope evidence for biodegradation of chlorinated ethenes at a fractured bedrock site. Environ Sci Technol 39(13):4848-4856

Chen S-J, Luo X-J, Mai B-X, Sheng G-Y, Fu J-M, Zeng EY (2006) Distribution and mass inventories of polycyclic aromatic hydrocarbons and organochlorine pesticides in sediments of the Pearl River estuary and the Northern South China Sea. Environ Sci Technol 40(3):709-714

Coffin RB, Miyares PH, Kelley CA, Cifuentes LA, Reynolds CM (2001) $\delta^{13} \mathrm{C}$ and $\delta^{15} \mathrm{~N}$ isotope analysis of TNT: two dimensional source identification. Environ Toxicol Chem 20(12):2676-2680

Craig DR, Mauro D, Saber D, Sirivedhin T, Philp RP, Allen JA (2005). Carbon isotope ratios of PAHs in urban background soil. In: Proceedings of the 3rd international conference on remediation of contaminated sediments. 57th annual meeting American Academy of Forensic Sciences, February 21-26, New Orleans

Day M, Aravena R, Hunkeler D, Gulliver T (2002) Application of carbon isotopes to document biodegradation of tert-butyl alcohol under field conditions. Contaminated Soil Sediment \& Water, August, pp 88-92

Drenzek NJ, Tarr CH, Eglinton TI, Heraty LJ, Sturchio NC, Shiner VJ, Reddy CM (2002) Stable chlorine and carbon isotopic compositions of selected semi-volatile organochlorine compounds. Org Geochem 33(4):437-444

Fang J, Kawamura K, Ishimura Y, Matsumoto K (2002) Carbon isotopic composition of fatty acids in the marine aerosols from the western North Pacific: implication for the source and atmospheric transport. Environ Sci Technol 36(12):2598-2604

Farran A, Grimalt J, Albaiges J, Botello AV, Macko SE (1987) Assessment of petroleum pollution in a Mexican river by molecular markers and carbon isotope ratios. Marine Pollut Bull 18(6):284288

Faure G, Mensing TM (2005) Isotopes: principles and applications. Wiley, Hoboken, NJ, pp 897

Finneran KT, Lovley DR (2001) Anaerobic degradation of methyl tertbutyl ether (MTBE) and tert-butyl alcohol (TBA). Environ Sci Technol 35(9):1785-1790

Franco MA, Viñas L, Soriano JA, de Armas D, González JJ, Beiras R, Salas N, Bayona JM, Albaigés J (2006) Spatial distribution and ecotoxicity of petroleum hydrocarbons in sediments from the Galicia continental shelf (NW Spain) after the Prestige oil spill. Marine Pollut Bull 53(5-7):260-271 
Fuentes HR, Jaffe R, Shrotriya RV (1996) Weathering of crude oil spills in seawater under simulated laboratory conditions. In: Proceedings of the 5th Latin American Congress on organic geochemistry, Cancun, Mexico, Abstracts. Mexican Petroleum Institute, Mexico City, Mexico, pp 310-312

Galimov EM (1985) The biological fractionation of isotopes. Academic Press, Orlando, pp 261

Glaser B, Dreyer A, Bock M, Fiedler S, Mehring M, Heitmann $\mathrm{T}$ (2005) Source apportionment of organic pollutants of a highway-traffic influenced urban area in Bayreuth (Germany) using biomarker and stable carbon isotope signatures. Environ Sci Technol 39(11):3911-3917

Gray R, Lacrampe-Couloume G, Gandhi D, Scow KM, Wilson RD, Mackay DM, Sherwood Lollar B (2002) Carbon and hydrogen isotopic fractionation during biodegradation of methyl tert-butyl ether. Environ Sci Technol 36(9):1931-1938

Griebler C, Safinowski M, Vieth A, Richnow HH, Meckenstock RU (2004) Combined application of stable carbon isotope analysis and specific metabolites determination for assessing in situ degradation of aromatic hydrocarbons in a tar oil-contaminated aquifer. Environ Sci Technol 38(2):617-631

Gürgey K, Philp RP, Clayton C, Emiroğlu H, Siyako M (2005) Geochemical and isotopic approach to maturity/source/mixing estimations for natural gas and associated condensates in the Thrace Basin, NW Turkey. Appl Geochem 20(11):20172037

Hammer BT, Kelley CA, Coffin RB, Cifuentes LA, Mueller JG (1998) ${ }^{13} \mathrm{C}$ values of polycyclic aromatic hydrocarbons collected from two creosote-contaminated sites. Org Geochem 152(1/2):4358

Hartman B, Hammond D (1981) The use of carbon and sulfur isotopes as a correlation parameter for source identification of beach tars in southern California. Geochim Cosmochim Acta 45:309-319

Haws NW, Ball WP, Bouwer EJ (2006) Modeling and interpreting bioavailability of organic contaminant mixtures in subsurface environments. J Contam Hydrol 82(3/4):255-292

Hayes JM, Freeman KH, Popp BN, Hoham CH (1990) Compound specific isotope analysis: a novel tool for reconstruction of ancient biogeochemical processes. Org Geochem 16(4-6):11151128

Heraty LJ, Fuller ME, Huang L, Abrajano T, Sturchio NC (1999) Isotopic fractionation of carbon and chlorine by microbial degradation of dichloromethane. Org Geochem 30(8):739-753

Hilkert AW, Douthitt CB, Schluter HJ, Brand WA (1999) Isotope ratio monitoring gas chromatography/mass spectrometry of $\mathrm{D} / \mathrm{H}$ by high temperature conversion isotope ratio mass spectrometry. Rapid Commun Mass Spectrom 13:1226-1230

Hillaire-Marcel C (1986) Isotopes and food. In: Fritz P, Fontes JCh (eds) Handbook of environmental isotope geochemistry. vol 2: the terrestrial environment, B, Chapter 12. Elsevier, Amsterdam, pp $507-548$

Hoeffs J (2004) Stable isotope geochemistry. Springer, Berlin, New York, pp 244

Holt BD, Sturchio NC, Abrajano TA, Heraty LJ (1997) Conversion of chlorinated volatile organic compounds to carbon dioxide and methyl chloride for isotopic analysis of carbon and chlorine. Anal Chem 69:2727-2733

Hong SH, Yim UH, Shim WJ, Oh JR (2005) Congener-specific survey for polychlorinated biphenlys in sediments of industrialized bays in Korea: regional characteristics and pollution sources. Environ Sci Technol 39(19):7380-7388

Horii Y, Kannan K, Petrick G, Gamo T, Falandysz J, Yamashita N (2005) Congener-specific carbon isotopic analysis of technical PCB and PCN mixtures using two-dimensional gas chromatography-isotope ratio mass spectrometry. Environ Sci Technol 39(11):4206-4212
Hough RL, Whittaker M, Fallick AE, Preston T, Farmer JG, Pollard SJT (2006) Identifying source correlation parameters for hydrocarbon wastes using compound-specific isotope analysis. Environ Pollut, in press

Hunkeler D, Aravena R (2000) Determination of compound-specific carbon isotope ratios of chlorinated methanes, ethanes, ethenes in aqueous samples. Environ Sci Technol 34:2839-2844

Hunkeler D, Aravena R, Butler BJ (1999) Monitoring microbial dechlorination of tetrachloroethene (PCE) in groundwater using compound-specific stable carbon isotope ratios: microcosm and field studies. Environ Sci Technol 33:2733-2738

Jarman WM, Hilkert A, Bacon CE, Collister JW, Ballschmitter P, Risebrough RW (1998) Compound specific carbon isotope analysis of Aroclors, Clophens, Kaneclors, Phenoclors. Environ Sci Technol 32(6):833-836

Jendrzejewski N, Eggenkamp HGM, Coleman ML (2001) Characterization of chlorinated hydrocarbons from chlorine and carbon isotopic compositions: scope of application to environmental problems. Appl Geochem 16(9/10):1021-1031

Kelley CA, Coffin RB, Cifuentes LA, Lantz SE, Mueller JG (1995) The use of GC/C/IRMS coupled with GC/MS to monitor biodegradation of petroleum hydrocarbons. Platform Abstracts of the Third International Symposium in Situ and On Situ Bioreclaimation, San Diego, CA

Kelley CA, Hammar BT, Coffin RB (1997) Concentrations and stable isotope values of BTEX in gasoline contaminated groundwater. Environ Sci Technol 31(9):2469-2472

Kolhatkar R, Kuder T, Philp P, Allen J, Wilson JT (2002) Use of compound-specific stable carbon isotope analyses to demonstrate anaerobic biodegradation of MTBE in groundwater at a gasoline release site. Environ Sci Technol 36:5139-5146

Krummen ML, Hilkert AW, Juchelka D, Duhr A, Schlueter H, Pesch $\mathrm{R}$ (2004) A new concept for isotope ratio monitoring liquid chromatography/mass spectrometry. Rapid Commun Mass Spectrom 18:2260-2266

Kuder T, Wilson JT, Kaiser P, Kolhatkar R, Philp P, Allen J (2005) Enrichment of stable carbon and hydrogen isotopes during anaerobic biodegradation of MTBE: microcosm and field evidence. Environ Sci Technol 39:213-220

Kvenvolden KA, Hostettler FD, Carlson PR, Bapp JB, Threlkeld CN, warden A (1995) Ubiquitous tar balls with a California-source signature on shorelines of Prince William Sound, Alaska. Environ Sci Technol 29(10):2684-2694

Lafargue E, Barker C (1988) Effect of water-washing on crude oil compositions. Am Assoc Petroleum Geolo Bull 72:263-276

Lee B-C, Shimizu Y, Matsuda T, Matsui S (2005) Characterization of polycyclic aromatic hydrocarbons (PAHs) in different size fractions in deposited road particles (DRPs) from Lake Biwa area, Japan. Environ Sci Technol 39(19):7402-7409

Lichtfouse E (2000) Compound-specific isotope analysis (CSIA). Application to archaeology, biomedical sciences, biosynthesis, environment, extraterrestrial chemistry, food science, forensic science, humic substances, microbiology, organic geochemistry, soil science and sport. Rapid Commun Mass Spectrom 14:13371344

Lichtfouse E, Schwarzbauer J, Robert D (eds) (2005). Environmental chemistry, green chemistry and pollutants in ecosystems. Sections: 1. Analytical chemistry. 2. Toxic metals. 3. Organic pollutants. 4. Polycyclic aromatic compounds. 5. Pesticides. 6. Green chemistry. 7. Ecotoxicology. Springer, Berlin Heidelberg New York, 69 chapters, $780 \mathrm{p}$

Macko SA, Parker PL, Botello AV (1981) Persistence of spilled oil in a Texas salt marsh. Environ Pollut Bull 2:119-128

Macko SA, Parker PL (1983) Stable nitrogen and carbon isotope ratios of beach tars on South Texas barrier islands. Marine Environ Res 10:93-103 
Mancini SA, Lacrampe-Couloume G, Jonker H, van Breukelen BN, Groen J, Volkering F, Sherwood Lollar B (2002) Hydrogen isotopic enrichment: an indicator of biodegradation at a petroleum hydrocarbon contaminated field site. Environ Sci Technol 36(11):2464-2470

Mancini SA, Ulrich AC, Lacrampe-Couloume G, Sleep B, Edwards EA, Sherwood Lollar B (2003) Carbon and hydrogen isotopic fractionation during anaerobic biodegradation of benzene. Appl Environ Microbiol 69:191-198

Mansuy L, Philp RP, Allen J (1997) Source identification of oil spills based on the isotopic composition of individual components in weathered oil samples. Environ Sci Technol 31(12):34173425

Mauro D, Saber D, Sirivedhin T, Philp RP, Allen JA (2005). Carbon isotope ratios of PAHs in urban background soil. In: Proceedings of the 3rd international conference on remediation of contaminated sediments, New Orleans, January 2005, Abstracts

Mazeas L, Budzinski H (2002) Molecular and stable carbon isotopic source identification of oil residues and oiled bird feathers sampled along the Atlantic Coast of France after the Erika oil spill. Environ Sci Technol 36(2):130-137

McRae C, Sun CG, Snape CE, Fallick AE, Taylor D (1999) $\delta^{13} C$ values of coal-derived PAHs from different processes and their application to source apportionment. Org Geochem 30(8):881889

McRae C, Snape CE, Sun C-G, Fabbri D, Tartari D, Trombini C, Fallick AE (2000) Use of compound-specific stable isotope analysis to source anthropogenic natural gas-derived polycyclic aromatic hydrocarbons in a lagoon sediment. Environ Sci Technol 34(22):4684-4686

Meckenstock RU, Morasch B, Warthmann RW, Schink B, Annweller E, Michaelis W, Richnow HH (1999) ${ }^{13} \mathrm{C} /{ }^{12} \mathrm{C}$ Isotope fractionation of aromatic hydrocarbons during microbial degradation. Environ Microbiol 1(5):409-414

Meckenstock RU, Morasch B, Kastner M, Vieth A, Richnow HH (2002) Assessment of bacterial degradation of aromatic hydrocarbons in the environment by analysis of stable carbon isotope fractionation. Water Air Soil Pollut Focus 2:141-152

Meckenstock RU, Morasch B, Griebler C, Richnow HH (2004a) Stable isotope fractionation analysis as a tool to monitor biodegradation in contaminated aquifers. J Contam Hydrol 75:215255

Meckenstock RU, Safinowski M, Griebler C (2004b) Anaerobic degradation of polycyclic aromatic hydrocarbons. FEMS Microbiol Ecol 49:27-36

Melander L, Saunders WH (1980) Reaction rates of isotopic molecules. Wiley, New York, pp 331

Merritt DA, Freeman KH, Ricci MP, Studley SA, Hayes JM (1995) Performance and optimization of a combustion interface for isotope ratio monitoring gas chromatography/mass spectrometry. Anal Chem 67:2461-73

Milkov AV (2005) Molecular and stable isotope compositions of natural gas hydrates: a revised global dataset and basic interpretations in the context of geological settings. Org Geochem 36(5):681702

Milner CWD, Rogers MA, Evans CR (1977) Petroleum transformations in reservoirs. J Geochem Expl 7:101-153

Morrill PL, LaCrampe-Couloume G, Slater GF, Sleep BE, Edwards EA,McMaster ML, Major DW, Sherwood Lollar B (2005) Quantifying chlorinated ethene degradation during reductive dechlorination at Kelly AFB using stable carbon isotopes. J Contam Hydrol 76:279-293

Norman AL, Hopper JF, Blanchard P, Ernst D, Brice K, Alexandroi N, Klouda G (1999) The stable carbon isotope composition of atmospheric PAHs. Atmos Environ 33(17):28072814
Numata M, Nakamura N, Koshikawa H, Terashima Y (2002) Chlorine isotope fractionation during reductive dechlorination of chlorinated ethenes by anaerobic bacteria. Environ Sci Technol 36(20):4389-4394

Ohe T, Watanabe T, Wakabayashi K (2004) Mutagens in surface waters: a review. Mutat Res Rev Mutat Res 567(2/3):109-149

Okuda T, Kumata H, Zakaria MP, Naraoka H, Ishiwatari R, Takada H (2002a) Source identification of Malaysian atmospheric polycyclic aromatic hydrocarbons nearby forest fires using molecular and isotopic compositions. Atmos Environ 36:611-618

Okuda T, Kumata H, Naraoka H, Ishiwatari R, Takada H (2002b) Vertical distributions and $\delta^{13} \mathrm{C}$ isotopic compositions of PAHs in Chidorigafuchi Moat sediment, Japan. Org Geochem 33(7):843848

Palmer SE (1993) Effect of biodegradation and water-washing on crude oil composition. In: Engel MH, Macko SE (eds) Organic geochemistry. Plenum Press, New York, pp 511-534

Peters KE, Fowler MG (2002) Applications of petroleum geochemistry to exploration and reservoir management. Org Geochem 332(1):536

Philp RP, Allen J, Kuder T (2002) The use of the isotopic composition of individual compounds for correlating spilled oils and refined products in the environment with suspected sources. Environ Forensics 3(3/4):341-348

Pond KL, Huang Y, Wang Y, Kulpa CF (2002) Hydrogen isotopic composition of individual $n$-alkanes as an intrinsic tracer for bioremediation and source identification of petroleum contamination. Environ Sci Technol 36(4):724-728

Reddy CM, Heraty LJ, Holt BD, Sturchio NC, Eglinton TI, Drenzek NJ, Xu L, Lake JL, Maruya KA (2000) Stable carbon isotope compositions of Aroclors and Aroclor contaminated sediments. Environ Sci Technol 34(13):2866-2870

Rogers KMMM (1999) Detection of petroleum contamination in river sediments from Quebec City region using GC-IRMS. Org Geochem 30(12):1559-1569

Saber D, Mauro D, Philp RP, Allen J, Kuder T (2003) Carbon isotope ratios of PAHs in urban background soil. In: Proceedings of the Battelle meeting, Orlando

Saber D, Mauro D, Philp RP, Allen JA (2005) Chemical fingerprinting of sediments and soils near a former MPG site. In: Proceedings of the 3rd international conference on remediation of contaminated sediments, New Orleans. Abstracts

Samara F, Tsai CW, Aga DS (2006) Determination of potential sources of PCBs and PBDEs in sediments of the Niagara River. Environ Pollut 139(3):489-497

Schirmer M, Butler BJ (2004) Transport behavior and natural attenuation of organic contaminants at spill sites. Toxicology 205(3):173179

Schmidt TC, Zwank L, Elsner M, Berg M, Meckenstock RU, Haderlein SB (2004) Compound-specific stable isotope analysis of organic contaminants in natural environments: a critical review of the state of the art, prospects, and future challenges. Anal Bioanal Chem 378:283-300

Schüth C, Taubald H, Bolaño N, Maciejczyk K (2003) Carbon and hydrogen isotope effects during sorption of organic contaminants on carbonaceous materials. J Contam Hydrol 64(3/4):269-281

Scow KM, Hicks KA (2005) Natural attenuation and enhanced bioremediation of organic contaminants in groundwater. Curr Opin Biotechnol 16:246-253

Sessions AL, Burgoyne TW, Schimmelmann A, Hayes JM (1999) Fractionation of hydrogen isotopes in lipid biosynthesis. Org Geochem 30(9):1193-1200

Sherwood Lollar B, Slater GF, Sleep B, Witt M, Klecka GM, Harkness M, Spivack J (2001) Stable carbon isotope evidence for intrinsic bioremediation of tetrachloroethene and trichloroethene at area 6 , Dover Air Force Base. Environ Sci Technol 35:261-269 
Shouakar-Stash O, Frape SK, Drimmie RJ (2003) Stable hydrogen, carbon and chlorine isotope measurements of selected chlorinated organic solvents. J Contam Hydrol 60(3/4):211-228

Shouakar-Stash O, Drimmie RJ, Frape SK (2005) Determination of inorganic chlorine stable isotopes by conditions flow isotope ratio mass spectrometry. Rapid Commun Mass Spectrom 19:121-127

Slater GF (2003) Stable isotope forensics-when isotopes work. Environ Forensics 4:13-23

Smallwood BJ, Philp RP, Allen JD (2002) Stable carbon isotopic composition of gasolines determined by isotope ratio monitoring gas chromatography mass spectrometry. Org Geochem 33:149-159

Smirnov A, Abrajano TA, Smirnov A, Stark A (1998) Distribution and sources of polycyclic aromatic hydrocarbons in the sediments of Lake Erie, Part 1. Spatial distribution, transport, and deposition. Org Geochem 29(5-7):1813-1828

Somsamak P, Cowan RM, Haggblom MM (2001) Anaerobic biotransformation of fuel oxygenates under different anoxic conditions. FEMS Microbiol Ecol 37:259-264

Song DL, Conrad ME, Sorenson KS, Alvarez-Cohen L (2002) Stable carbon isotope fractionation during enhanced in situ bioremediation of trichloroethene. Environ Sci Technol 36:2262-2268

Stark A, Abrajano T, Hellou J, Metcalf-Smith JL (2003) Molecular and isotopic characterization of polycyclic aromatic hydrocarbon distribution and sources at the international segment of the St. Lawrence River. Org Geochem 34(2):225-237

Sturchio NC, Clausen JL, Heraty L, Huang L, Holt BD, Abrajano $\mathrm{T}$ (1998) Chlorine isotope investigation of natural attenuation of trichloroethene in an aerobic aquifer. Environ Sci Technol 32(20):3037-3042

Thornton SF, Lerner DN, Banwart SA (2001) Assessing the natural attenuation of organic contaminants in aquifers using plume-scale electron and carbon balances: model development with analysis of uncertainty and parameter sensitivity. J Contam Hydrol 53(3/4):199-232
Wang Y, Huang Y, Huckins JN, Petty JD (2004) Compound-specific carbon and hydrogen. Environ Sci Technol 38(13):3689-3697

Warmerdam EM, Frape SK, Aravena R, Drimmie RJ, Flatt H, Cherry JA (1995) Stable chlorine and carbon isotope measurements of selected chlorinated organic solvents. Appl Geochem 10(5):547552

Wassenaar LI, Hobson KA (2000) Improved method for determining the stable-hydrogen isotopic composition $(\delta \mathrm{D})$ of complex organic materials of environmental interest. Environ Sci Technol 34(11):2354-2360

Wen S, Feng Y, Yu Y, Bi X, Wang X, Sheng G, Fu J, Peng P (2005) Development of a compound-specific isotope analysis method for atmospheric formaldehyde and acetaldehyde. Environ Sci Technol 39(16):6202-6207

Wiesenberg GLB, Schwarzbauer J, Schmidt MWI, Schwark L (2004) Source and turnover of organic matter in agricultural soils derived from $n$-alkane/ $n$-carboxylic acid compositions and C-isotope signatures. Org Geochem 35(11/12):1371-1393

Wilcke W, Krauss M, Amelung W (2002) Carbon isotope signature of polycyclic aromatic hydrocarbons (PAHs): evidence for different sources in tropical and temperate environments? Environ Sci Technol 36(16):3530-3535

Zwank L, Berg M, Elsner M, Schmidt TC, Schwarzenbach RP, Haderlein SB (2005) New evaluation scheme for two-dimensional isotope analysis to decipher biodegradation processes: application to groundwater contamination by MTBE. Environ Sci Technol 39(18):7344-7344

Zwank L, Berg M, Schmidt TC, Haderlein SB (2003) Compoundspecific carbon isotope analysis of volatile organic compounds in the low-microgram per liter range. Anal Chem 75:5575-5583 